\title{
Assessment of Awareness, Knowledge, Attitude, and the Practice of Vitamin D among the General Public in Malaysia
}

\section{*Ali Qais Blebil ${ }^{1}$, Juman Abdulelah Dujaili' ${ }^{1}$, Enie Teoh ${ }^{2}$, Pik Sze Wong ${ }^{2}$, Bhuvan KC ${ }^{1}$}

${ }^{1}$ Lecturer, ${ }^{2}$ Pharmacy Graduate, School of Pharmacy, Monash University Malaysia

\section{*Corresponding Author:}

\section{Ali Qais Blebil}

Email: aliblebil@yahoo.com

\section{ABSTRACT}

Introduction: Vitamin D deficiency is becoming a global epidemic, which is still undertreated despite increased treatment availability and increase in therapeutic options. This study aimed to explore the awareness, knowledge, attitude and practices regarding Vitamin D among the general public in Malaysia.

Methods: A cross-sectional survey was carried out in a public area using a convenience sampling technique to recruit participants around Selangor and Kuala Lumpur shopping malls area. An anonymous self-administered questionnaire was used for data collection and it was circulated to 603 Malaysian. A total of 400 participants were completed and returned to the researchers.

Result: Although $90.5 \%$ of the participants have heard/learnt about Vitamin D. About $78.0 \%$ of them showed limited knowledge about some aspects of Vitamin D with (mean $\pm \mathrm{SD}=1.78 \pm 0.894$ ). Additionally, there was a negative attitude towards Vitamin D and sunlight exposure. For instance, nearly $70.0 \%$ of the respondents did not like to expose themselves to sunlight. Only $30.0 \%$ of the participants had taken Vitamin D supplement before. There is a small, positive correlation between the knowledge score and education level, rho $=0.124, \mathrm{n}=400, \mathrm{P}=0.013$, with a higher score associated with higher education level.

Conclusion: The findings provided a piece of contemporary real-world evidence on the lack of knowledge and practices about Vitamin D among the general public. Therefore, extensive health educational campaigns for the public should be implemented by the government to raise their knowledge on the importance of Vitamin D.

Keywords: knowledge; practice; vitamin D; public; Malaysia

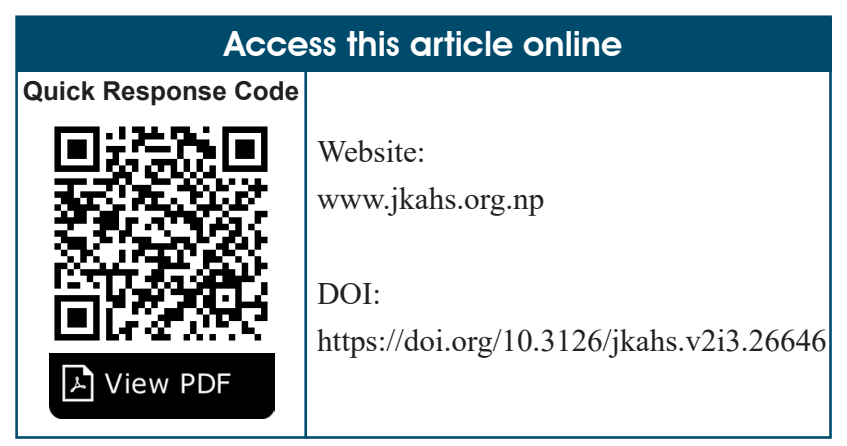

\section{Article Info.}

\section{How to cite this article?}

Blebil AQ, Dujaili JA, Teoh E, Wong PS, KC B. Assessment of Awareness, Knowledge, Attitude, and the Practice of Vitamin D among the General Public in Malaysia. Journal of Karnali Academy of Health Sciences. 2019;2(3): 171-180.

Received: 3 Oct., Accepted: 4 Nov., Published: 11 Dec. 2019

Conflict of Interest: None, Source of Support: None 


\section{INTRODUCTION}

Vitamin D can be obtained from dietary sources such as dairy products, oily fish, drugs and supplements. ${ }^{1}$ Besides, vitamin D is synthesised endogenously following skin exposure to the sun. Since Vitamin D that are naturally found in foods are insufficient for body needs, the main sources of Vitamin D is therefore obtained from cutaneous synthesis through sunlight exposure. ${ }^{2}$ Hence, inadequacy of sunlight exposure is then the leading cause of vitamin D deficiency. ${ }^{3,4}$ Thus, vitamin D status is affected by daily outdoor activities, proportion of body surface exposed to sunlight, seasons and geographic latitude. ${ }^{5}$ Other than insufficient sunlight exposure, vitamin D deficiency can also caused by altered pathophysiological conditions such as increased catabolism of vitamin $\mathrm{D}$, decreased absorption of vitamin $\mathrm{D}$, heritable disorders such as ricket and acquired disorders such as hyperthyroidism. ${ }^{4}$

Vitamin D deficiency is a major public health problem worldwide in all age groups, even in those residing in countries with low latitude. ${ }^{6}$ Despite of advancement in medical sciences still Vitamin D deficiency is undertreated and underdiagnosed. ${ }^{7-9} \mathrm{~A}$ systematic review conducted in 2013 showed an overview of Vitamin D status globally and revealed that vitamin D deficiency is significantly present all over the world in all age groups, despite countries that have sun exposure all year-round including Hawaii, India, Turkey, Saudi Arabia and Iran. ${ }^{9-14}$ There is a significant presence of Vitamin D deficiency in the Middle East, especially among females. ${ }^{6}$ A qualitative study performed in UK reported limited knowledge about the health benefits of vitamin $\mathrm{D}$ and confusion about both the risks and benefits of sun exposure and vitamin D food sources. ${ }^{15}$ Similarly, the findings of the studies from Australia, China, France and Saudi Arabia showed that the populations had poor knowledge, despite having good vitamin D awareness. ${ }^{16-19}$

Malaysia as a tropical country located near the Equator, and has an abundance of sunshine year round. One might expect a low prevalence of Vitamin
D deficiency among Malaysians public. However, this is not necessary the case, as shown in several studies.20-22 In Malaysia the increasing trend of using sunscreen, excessive use of umbrella among women, clothing and limited outdoor activities have an impact on the vitamin D levels. Furthermore, among the ethnic groups in Malaysia; the Malay and Indian females were six times more likely to have vitamin D deficiency compared to Chinese females which may be due to their dietary intake and genetic makeup. 23

Vitamin D deficiency is now a common health issues and has become an unrecognised epidemic around the world, including Malaysia. However, there is no specific public health program that emphasizes on the populations' vitamin D status up-to-date.22 Based on the previous, this study aimed to evaluate the awareness and knowledge regarding Vitamin D, attitudes toward sun exposure and practices including social and cultural factors that might lead to vitamin D deficiency among Malaysians. The findings will provide evidence for developing appropriate educational interventions and health promotions for the public, thus improving the understanding and knowledge regarding the importance of vitamin D and eventually decreasing the risk of Vitamin D deficiency in Malaysia.

\section{MATERIAL AND METHODS}

\section{Study Design and Population}

A cross-sectional study was conducted among general population at Klang Valley area of Malaysia from November 2018 to January 2019. A random convenient sampling technique was used for the data collection, and a total of 400 participants were enrolled for this study. Verbal consent was obtained from each participant after explaining the nature and objective of the study. The study population was Malaysian adults aged 18 years and above from both genders and willing to participate in this research. 


\section{Assessment Tool}

An anonymous data collection form was used to attain the objectives of the study. The items of the data collection form was adopted and modified based on a literature review of previous studies. ${ }^{16,17,24,25}$ The tool comprised mainly of four parts. Part A focused on socio-demographic information of the respondents such as age, ethnicity, gender, education level, monthly income and occupation, previous medical and surgical history. Part B was more oriented towards the awareness and the knowledge of Vitamin D. The participants were asked whether they heard of Vitamin D before and their sources of information, knowledge about the sources of Vitamin D and health effects of Vitamin D. The score of Knowledge was evaluated by giving 0 to the wrong answer and 1 to correct answer. The score ranged from 0 (minimum) to 4 (maximum). A cut off score of $<3$ was regarded as poor knowledge whereas $\geq 3$ was regarded as adequate knowledge about Vitamin D. For each participant, knowledge scores were calculated and added up to give a total knowledge score. Knowledge score ranged from 4 (maximum) to 0 (minimum). In part $\mathrm{C}$, an eight-item Likert-type scale ranging from strongly disagree to strongly agree was applied to record the variation in attitudes. Few statements were provided like the importance of Vitamin D for their health, their exposure to sunlight, whether exposure to sunlight is harmful for the skin, concerns about their Vitamin D status and willingness to undergo test for Vitamin D. The participants were also asked about the use of sun protection such as sunscreen or umbrella and whether taking Vitamin D supplement can reduce the risk of Vitamin D deficiency. Each item of this part was labelled with a negative or a positive attitude. A score of 0 was given to the negative attitude and 5 was given to the positive attitude. The total score ranges from a minimum of 0 to a maximum of 40 . A cut off score of $\leq 20$ was considered as negative attitude whereas $>20$ was considered as positive attitudes towards Vitamin D and sunlight exposure. The part D the last section of the tool, consisted of questions related to the practices of Vitamin D and sunlight exposure in daily routine like consumption of Vitamin
D supplement, involvement in any outdoor activities, and body parts that were exposed to sunlight during outdoor activities.

\section{Statistical Analysis and Ethical Approval}

According to the Raosoft sample size calculator, the required sample size was 377 .The sample size was calculated according to a $95.0 \%$ confidence level and a 5.0\% margin of error. However, final sample size collected was 400 to avoid data bias and drawback. Statistical Package for the Social Sciences (SPSS) version 24.0was used for analysis of data. Descriptive statistics were used to characterize the study cohort and to determine the frequencies of participants' knowledge of vitamin D deficiency. Categorical variables were reported as frequency and percentages while continuous variables were expressed as mean \pm standard deviation. Chi-square tests were used to assess the differences and significance between the study variables. Spearman's rho product-moment correlation coefficient was performed to investigate the relationship between sociodemographic characteristics and practice measure and knowledge score regarding Vitamin D supplement. A p value of $<0.05$ was considered statistically significant. Ethical approval was obtained from Monash University Research Ethics Committee.

\section{RESULTS}

\section{Sociodemographic and Clinical Information}

Out of 603 individuals who were invited to participate in this study, 400 completed the study tool, giving a response rate of $66.3 \%$. Majority of the respondents $(64.3 \%)$ were females and Chinese (72.5\%). The mean age and SD of the participant was 29.62 \pm 10.6 years. About $86 \%$ were having college/ university level education and $44.8 \%$ were having private job/self-employed; followed by $36.8 \%$ were students. Nearly $23 \%$ of the participants reported of having suffering from health conditions, while $34.8 \%$ responded to having muscle pain and fatigue of whom majority were not taking any medication for that (Table 1). 
Table 1: Demographic characteristics and Clinical information of the study participants $(\mathrm{N}=400)$

\begin{tabular}{cc}
\hline Variables & Frequency $(\%)$ \\
\hline
\end{tabular}

Age (mean $\pm \mathrm{SD})$ in years

$29.62 \pm 10.6$

Gender

$\begin{array}{ll}\text { Male } & 143(35.8) \\ \text { Female } & 257(64.3)\end{array}$

Ethnicity

$\begin{array}{lc}\text { Malay } & 70(17.5) \\ \text { Chinese } & 290(72.5) \\ \text { Indian } & 26(6.5) \\ \text { Others } & 14(3.5)\end{array}$

Education Level

No formal education

Primary School

Secondary School

College/University

$342(85.5)$

Occupation

Government

Private/self-employed

$179(44.8)$

Retired

$10(2.5)$

Student

$147(36.8)$

Unemployed

$14(3.5)$

Monthly income $* \dagger$

$\begin{array}{ll}\leq \text { RM } 1000 & 148(38.0) \\ \text { RM 1001-3000 } & 79(20.3) \\ \text { RM 3001-5000 } & 99(25.4) \\ >\text { RM 5000 } & 63(16.2)\end{array}$

Do you have any kind of health condition?
Yes
$91(22.8)$
No
$309(77.3)$

Do you suffer from muscle pain and fatigue?
Yes
$139(34.8)$
No
$261(65.3)$

If yes, do you take treatment for muscle pain and fatigue? $* *$

\begin{tabular}{cl} 
Yes & $51(36.7)$ \\
No & $88(63.3)$ \\
\hline
\end{tabular}

* Total $\mathrm{N}=389 ; * *$ Total $\mathrm{N}=$ $139 ; \dagger 1 \mathrm{RM}=0.24$ USD.

\section{Awareness of Public Regarding Vitamin D}

As Shown in Table 2, around $91 \%$ of the participants have heard about Vitamin D, and of whom 52.0\% got their information about Vitamin D from either school/ university, or $26.3 \%$ from relatives/friends.

Table 2: Awareness and source of information regarding Vitamin $D(N=400)$

\begin{tabular}{lc}
\hline \multicolumn{1}{c}{ D } & \multicolumn{1}{c}{ (\%) } \\
\hline $\begin{array}{l}\text { Have you ever heard/learnt about } \\
\text { vitamin D? }\end{array}$ & $362(90.5)$ \\
Yes & $38(9.5)$ \\
No & \\
Where/from whom did you hear & \\
of vitamin D? & $38(9.5)$ \\
At your physician's & $49(12.3)$ \\
At another healthcare & \\
professional's & $59(14.8)$ \\
In newspapers & $41(10.3)$ \\
In magazines & $28(7.0)$ \\
On the radio & $64(16.0)$ \\
On the television & $105(26.3)$ \\
From relatives or friends & $208(52.0)$ \\
At school/university & $44(11.0)$ \\
Elsewhere & $22(5.5)$ \\
I don't remember & \\
\hline
\end{tabular}

\section{Knowledge Regarding Vitamin D}

In terms of knowledge, the overall average knowledge score among general public was $1.7(\mathrm{SD}=0.89)$ out of 4 . Nearly $78 \%$ of them showed poor knowledge (the score was $<3$ ) and only $22.5 \%$ showed adequate knowledge (the score was $\geq 3$ ) regarding Vitamin D. the study findings revealed that nearly $37 \%$ of the respondents chose that our body get Vitamin D from multiple resources (diet, sun exposure, and Vitamin D supplements) which consider low rate (Table 3). Majority of the participants (94.0\%) believed that breast feeding is the most appropriate source of vitamin $\mathrm{D}$ for babies. However, more than half of the 
participants recognised bone disease and osteoporosis as the health effects of Vitamin D deficiency and 66.0\% agreed on taking Ca supplements will help in maintaining vitamin D levels in the body. On the other hand, half of the participants agreed that exposure to sunlight is harmful from the skin whereas half of them disagreed.

Table 3: Responses to knowledge regarding Vitamin D ( $N=400)$

\begin{tabular}{|c|c|c|c|}
\hline \multirow{2}{*}{$\begin{array}{l}\text { Variables } \\
\text { According to you, is Vitamin D relevant for the following } \\
\text { health conditions? }\end{array}$} & \multicolumn{3}{|c|}{ Frequency (\%) } \\
\hline & Yes & No & I don't know \\
\hline Bone diseases & $270(67.5)$ & $40(10.0)$ & $90(22.5)$ \\
\hline Osteoporosis & $224(56.0)$ & 47 (11.8) & $129(32.3)$ \\
\hline Rickets & $173(43.3)$ & $64(16.0)$ & $163(40.8)$ \\
\hline Cancer & $65(16.3)$ & $164(41.0)$ & $171(42.8)$ \\
\hline Skin Cancers & $142(35.5)$ & $127(31.8)$ & $131(32.8)$ \\
\hline Kidney diseases & $63(15.8)$ & $160(40.0)$ & $177(44.3)$ \\
\hline Diabetes & $49(12.3)$ & $188(47.0)$ & $163(40.8)$ \\
\hline Heart diseases & $71(17.8)$ & $167(41.8)$ & $162(40.5)$ \\
\hline Alzheimer's & $58(14.5)$ & $159(39.8)$ & $183(45.8)$ \\
\hline Psychiatric diseases & $51(12.8)$ & $164(41.0)$ & $185(46.3)$ \\
\hline Pregnancy & $125(31.3)$ & $121(30.3)$ & $154(38.5)$ \\
\hline No health effect & $29(7.2)$ & $255(63.7)$ & $116(29.0)$ \\
\hline \multicolumn{4}{|l|}{ Where do you think the body gets vitamin D from? } \\
\hline Diet & & $77(19.3)$ & \\
\hline Sunlight exposure & & $134(33.5)$ & \\
\hline Vitamin D supplements & & $138(34.5)$ & \\
\hline All of the previous options & & $149(37.3)$ & \\
\hline I don't know & & $26(6.5)$ & \\
\hline \multicolumn{4}{|l|}{$\begin{array}{l}\text { What is the method of feeding for babies which is the } \\
\text { most appropriate source of vitamin D? }\end{array}$} \\
\hline Breastfeeding & & $376(94.0)$ & \\
\hline Artificial feeding & & $24(6.0)$ & \\
\hline \multicolumn{4}{|l|}{ Vitamin D is synthesized inside our body? } \\
\hline Yes & & $276(69.0)$ & \\
\hline No & & $124(31.0)$ & \\
\hline \multicolumn{4}{|l|}{$\begin{array}{l}\text { Taking Ca supplements helps in maintaining vitamin D } \\
\text { levels in the body? }\end{array}$} \\
\hline True & & $264(66.0)$ & \\
\hline False & & $136(34.0)$ & \\
\hline \multicolumn{4}{|l|}{ Exposure to sunlight is harmful for the skin? } \\
\hline True & & $198(49.5)$ & \\
\hline False & & $202(50.5)$ & \\
\hline \multicolumn{4}{|l|}{ What type of food is a good source of vitamin D? } \\
\hline Vegetables \& Fruits & & $129(32.3)$ & \\
\hline Milk/dairy products & & $208(52.0)$ & \\
\hline Fatty fish (salmon, sardines) & & $145(36.3)$ & \\
\hline Olive oil & & $82(20.5)$ & \\
\hline Eggs & & $93(23.3)$ & \\
\hline I don't know & & $108(27)$ & \\
\hline
\end{tabular}


Knowledge was assessed by giving 1 to correct answer and 0 to the wrong answer. Knowledge score ranged from 4 (maximum) to 0 (minimum). A cut off level of $<3$ was considered as poor whereas $\geq 3$ was considered as adequate knowledge.

\section{Attitude towards Vitamin D and Sunlight Exposure}

As shown in Table 4, although the majority of the participants (82\%) agreed that Vitamin D is important to our health and above $60 \%$ of them were willing to undergo for Vitamin D test if they needed.The findings revevealed that More than half(52.5\%) of the participants did not like to expose themselves to sunlight and $17.5 \%$ of them believed (agreed and strongly agreed) that they were in danger of not getting enough Vitamin $\mathrm{D}$ if they regularly protected their skin from the sun. In addition, $21.8 \%$ of the respondents were concerned that their current Vitamin D might be too low.

\section{Table 4: Attitude towards Vitamin D and sunlight exposure $(\mathrm{N}=400)$}

\begin{tabular}{lccccc}
\hline \multicolumn{1}{c}{ Statements } & $\begin{array}{c}\text { Strongly } \\
\text { disagree }\end{array}$ & Disagree & Unsure & Agree & $\begin{array}{c}\text { Strongly } \\
\text { agree }\end{array}$ \\
\hline $\begin{array}{l}\text { I think vitamin D is important } \\
\text { for our health }\end{array}$ & $43(10.8)$ & $13(3.3)$ & $16(4.0)$ & $158(39.5)$ & $170(42.5)$ \\
$\begin{array}{l}\text { I like to expose to sunlight all } \\
\text { the time }\end{array}$ & $68(17.0)$ & $142(35.5)$ & $68(17.0)$ & $100(25.0)$ & $22(5.5)$ \\
$\begin{array}{l}\text { I am often use a parasol } \\
\text { (sunshade or umbrella) to shade } \\
\text { from the sun }\end{array}$ & $40(10.0)$ & $121(30.3)$ & $80(20.0)$ & $125(31.3)$ & $34(8.5)$ \\
$\begin{array}{l}\text { The exposure to sunlight is } \\
\text { harmful for the skin }\end{array}$ & $31(7.8)$ & $105(26.3)$ & $94(23.5)$ & $128(32.0)$ & $42(10.5)$ \\
$\begin{array}{l}\text { If I regularly protect my skin } \\
\text { from the sun, I am in danger of } \\
\text { not getting enough vitamin D }\end{array}$ & $39(9.8)$ & $148(37.0)$ & $143(35.8)$ & $58(14.5)$ & $12(3.0)$ \\
$\begin{array}{l}\text { I am concerned that my current } \\
\text { vitamin D levels might be too } \\
\text { low }\end{array}$ & $45(11.3)$ & $109(27.3)$ & $159(39.8)$ & $71(17.8)$ & $16(4.0)$ \\
$\begin{array}{l}\text { I am willing to undergo test for } \\
\text { vitamin D if a medical condition } \\
\text { demands it }\end{array}$ & $38(9.5)$ & $37(9.3)$ & $81(20.3)$ & $182(45.5)$ & $62(15.5)$ \\
$\begin{array}{l}\text { Taking Vitamin D supplements } \\
\text { reduces the risk of Vitamin D } \\
\text { deficiency }\end{array}$ & $32(8.0)$ & $37(9.3)$ & $64(16.0)$ & $198(49.5)$ & $69(17.3)$ \\
\hline
\end{tabular}

\section{Practices about Vitamin D and Sunlight Exposure in Daily Routine}

As Shown in Table 5, only 30.3\% mentioned that they had taken Vitamin D supplement before, witha majority of them $82.4 \%$ reported of oral dosage form preference in form of pills/tablets.

In addition, $69 \%$ of the respondents were involved in outdoor activities and nearly $76 \%$ reported to be exposed to sunlight. Moreover, more than half of those surveyed (54\%) reported face, arms and half legs as the most exposed parts of the body to sunlight. 
Table 5: Responses to practices related to Vitamin D $(n=400)$

Variables

Frequency $(\%)$

Ever taken Vitamin D supplement

Yes

No

If yes, what is your preferred form of consuming a supplement? *
Syrup
Drops
Pills/tablets/granules
Injection

Are you involved in any kind of outdoor activity?

Yes

$276(69.0)$

No

Do you expose to the sunlight?

Yes

No

Which part of your body gets exposed to sunlight while outdoors activity?

Only face

Only arms

Both face and arms

Face, arms, and half legs

$216(54.0)$

*Total $\mathrm{N}=284$

\section{DISCUSSION}

The findings of this clearly showed that there was an inadequacy of knowledge among the public towards Vitamin D. This is accordance to the previously studies, where majority of the population demonstrated a knowledge deficit towards vitamin D and its deficiency. ${ }^{26-28}$ This study found most of the participants knew that Vitamin D deficiency is related to bone diseases and osteoporosis, but they were not aware that Vitamin D is also related to other health conditions such as cardiovascular diseases, diabetes and pregnancies. Our findings are aligned to results of previous studies. ${ }^{16,29-32}$ It had shown that breast milk contains an insufficient amount of vitamin D for infants and thus, exclusively breastfed infants should be supplemented with vitamin D. ${ }^{33}$ However, only $6 \%$ of the participants recognised that formula milk is the source of Vitamin D for infants instead of breast milk, regardless of gender. The possible reason for this might be due to the opinion of public that breast milk contains all required nutrients for infants. However, although breast milk provides babies with the best source of nutrients, it may not provide the adequate amount of vitamin $\mathrm{D}$ that is needed to absorb calcium. . $^{33,34}$

The study demonstrated negative attitudes of participants towards Vitamin D and sunlight exposure, which was also reported in the previous studies. ${ }^{16,24,}$ 28, 35 Although majority of them acknowledged the importance of Vitamin D for their health, they disliked exposing themselves under the sun, even among those who has adequate knowledge about vitamin D. ${ }^{16,24}$ Based on the findings, it can be speculated that the reason of sunlight avoidance may be caused by the changes in lifestyle due to modernization and to have a paler skin in order to blend into the current cultural trend. ${ }^{16,28}$ Moreover, it might be due to awareness of the harmful consequences of sunlight exposure such as skin cancer and skin ageing. ${ }^{16,36}$ Furthermore, negative attitudes can also be seen when most of the participants were not fear of getting insufficient Vitamin D if they regularly protecting their skin from the sun. The study cohort also believed that their current Vitamin D level is not too low. Perceived susceptibility of a person's vulnerability to contract a condition or disease can affect his/her attitude in taking certain preventive health actions. ${ }^{37}$ This is due to a perception that Vitamin D deficiency is uncommon among the society but in fact it is now prevalent all around the world. ${ }^{7,8}$

Interestingly, despite the negative attitudes observed, majority of the participants showed a positive approach towards sunlight exposure in their practices. Most of them were involved in outdoor activities and exposed to sunlight in their daily routine. The likely reason for this may be due to the location of Malaysia which is around the equator, receiving sunlight all year round and this allow the people to expose to sunlight once they are in the outdoors. Moreover, regardless of sex, body parts that were exposed to sunlight the most 
were face, arms and half legs. Despite $90.5 \%$ of those surveyed having heard of Vitamin D, a majority had never taking a Vitamin D supplement. Although they might know the benefits of Vitamin D, they chose not to take the supplement. However, this study showed a significant correlation among people who has ever taken Vitamin D supplement and higher knowledge score. This shows that when the public has adequate knowledge regarding vitamin $\mathrm{D}$ and is aware of the consequences related to Vitamin D deficiency, there is a higher chance of them taking Vitamin D supplement. This result is similar to a study carried out in Malaysia. ${ }^{38}$ Besides, based on 284 participants, the most preferred form of Vitamin D supplement consumption is pills or tablets form. This information can be used by the health industry to promote this form of Vitamin D supplement and encourage society to take them while ensuring compliance.

\section{Strengths and Limitations of the Present Study}

The current study was conducted in multiple shopping malls around the Kuala Lumpur and Selangor states which is multi-centred and thus, likely to be generalizable to the whole population in Malaysia. On the other hand, there are few limitations related to the methodology of this study. The design of the assessment tool did not include enough questions to cover all the aspect of the knowledge regarding Vitamin D, due to time constriction to run this study, as this is an undergraduate pharmacy project. However, we asked about Vitamin D relevant health conditions, source of Vitamin D, type of food that contains Vitamin $\mathrm{D}$, whether Vitamin $\mathrm{D}$ is being synthesised in the body the knowledge part of this survey. Secondly, we have a lesser sample size in the older age group compared to young adults. This may due to our approach in shopping malls where younger generation tends to be more active and willingly participate in our survey. Despite these limitations, our data provides important information and understanding towards Vitamin D among Malaysian adults.

\section{CONCLUSION}

In summary, the findings of this study show that there is a lack of awareness and knowledge of Vitamin D among Malaysian public. Further research should investigate the level of the Vitamin D of the participants via more extensive and validated survey to correlate their knowledge, attitudes and perceptions with levels. Thus, extensive health education campaigns for the public should be implemented, especially to the rural area residents.

\section{REFERENCES}

1. Nutrition SACo. Vitamin D and Health 2016 [Available from: https://assets.publishing. service.gov.uk/government/uploads/system/ uploads/attachment_data/file/537616/SACN_ Vitamin_D_and_Health_report.pdf.

2. Grant WB, Holick MF. Benefits and requirements of vitamin $\mathrm{D}$ for optimal health: a review. Altern Med Rev. 2005;10(2):94-112.

3. Holick MF, Binkley NC, Bischoff-Ferrari HA, Gordon CM, Hanley DA, Heaney RP, et al. Evaluation, treatment, and prevention of vitamin D deficiency: an Endocrine Society clinical practice guideline. J Clin Endocrinol Metab. 2011;96(7):1911-30.

4. Holick MF. Vitamin D deficiency. N Engl J Med. 2007;357(3):266-81.

5. Zittermann A, Gummert JF. Sun, vitamin D, and cardiovascular disease. J Photochem Photobiol B. 2010;101(2):124-9.

6. Bjørklund G. Vitamin D deficiency: a global health problem. Peertechz J Environ Sci Toxicol 1 (1): 023. 2016;24.

7. Saad K, Abdel-rahman AA, Elserogy YM, Al-Atram AA, Cannell JJ, Bjørklund G, et al. Vitamin D status in autism spectrum disorders and the efficacy of vitamin D supplementation in autistic children. Nutr Neurosci. 2016;19(8):346-51.

8. Kočovská E, Fernell E, Billstedt E, Minnis H, Gillberg C. Vitamin D and autism: clinical review. Res Dev Disabil. 2012;33(5):1541-50. 
9. Zhu D-m, Liu Y, Zhang A-g, Chu Z-x, Wu Q, Li H, et al. High levels of vitamin D in relation to reduced risk of schizophrenia with elevated C-reactive protein. Psychiatry Res. 2015;228(3):565-70.

10. Schoenmakers I, Goldberg GR, Prentice A. Abundant sunshine and vitamin D deficiency. Br J Nutr. 2008;99(6):1171-3.

11. Holick MF. Vitamin D:A millenium perspective. J Cell Biochem. 2003;88(2):296-307.

12. Gouni-Berthold I, Krone W, Berthold HK. Vitamin D and cardiovascular disease. Curr Vasc Pharmacol. 2009;7(3):414-22.

13. Dalgård C, Petersen MS, Weihe $\mathrm{P}$, Grandjean $\mathrm{P}$. VitaminDstatusinrelationtoglucosemetabolism and type 2 diabetes in septuagenarians. Diabetes Care. 2011;34(6):1284-8.

14. Alharbi FM. Update in vitamin D and multiple sclerosis. Neurosciences. 2015;20(4):329.

15. Palacios C, Gonzalez L. Is vitamin D deficiency a major global public health problem? The Journal of steroid biochemistry and molecular biology. 2014;144:138-45.

16. Soliman A. Vitamin D deficiency: A major global epidemic that requires effective strategy and guidelines for management. Indian $\mathrm{J}$ Endocrinol Metab. 2016;0(0):0.

17. Naeem Z. Vitamin d deficiency-an ignored epidemic. International journal of health sciences. 2010;4(1):V.

18. O'Connor C, Glatt D, White L, Revuelta Iniesta R. Knowledge, Attitudes and Perceptions towards Vitamin D in a UK Adult Population: A Cross-Sectional Study. Int J Environ Res Public Health. 2018;15(11):2387.

19. Rahnavard Z, Eybpoosh S, Homami MR, Meybodi HA, Azemati B, Heshmat R, et al. Vitamin D deficiency in healthy male population: Results of the Iranian multi-center osteoporosis study. Iran J Public Health. 2010;39(3):45.

20. Binkley N, Novotny R, Krueger D, Kawahara T, Daida YG, Lensmeyer G, et al. Low vitamin D status despite abundant sun exposure. J Clin Endocrinol Metab. 2007;92(6):2130-5.
21. Guzel R, Kozanoglu E, Guler-Uysal F, Soyupak S, Sarpel T. Vitamin D status and bone mineral density of veiled and unveiled Turkish women. J Womens Health Gend Based Med. 2001;10(8):765-70.

22. Harinarayan C. Prevalence of vitamin D insufficiency in postmenopausal south Indian women. Osteoporos Int. 2005;16(4):397-402.

23. Lips P. Vitamin D status and nutrition in Europe and Asia. The Journal of steroid biochemistry and molecular biology. 2007;103(3-5):620-5.

24. Kotta S, Gadhvi D, Jakeways N, Saeed M, Sohanpal R, Hull S, et al. "Test me and treat me"-attitudes to vitamin D deficiency and supplementation: a qualitative study. BMJ Open. 2015;5(7):e007401.

25. Kung AW, Lee K-K. Knowledge of vitamin D and perceptions and attitudes toward sunlight among Chinese middle-aged and elderly women: a population survey in Hong Kong. BMC Public Health. 2006;6(1):226.

26. Vu LH, van der Pols JC, Whiteman DC, Kimlin MG, Neale RE. Knowledge and attitudes about vitamin $\mathrm{D}$ and impact on sun protection practices among urban office workers in Brisbane, Australia. Cancer Epidemiology and Prevention Biomarkers. 2010;19(7):1784-9.

27. Aljefree N, Lee P, Ahmed F. Exploring Knowledge and Attitudes about Vitamin D among Adults in Saudi Arabia: A Qualitative Study. Healthcare. 2017;5(4):76.

28. Deschasaux M, Souberbielle J-C, Partula V, Lécuyer L, Gonzalez R, Srour B, et al. What Do People Know and Believe about Vitamin D? Nutrients. 2016;8(11):718.

29. Al-Sadat N, Majid HA, Sim PY, Su TT, Dahlui M, Bakar MFA, et al. Vitamin D deficiency in Malaysian adolescents aged 13 years: findings from the Malaysian Health and Adolescents Longitudinal Research Team study (MyHeARTs). BMJ open. 2016;6(8):e010689.

30. Moy F-M, Bulgiba A. High prevalence of vitamin $\mathrm{D}$ insufficiency and its association with obesity and metabolic syndrome among Malay 
adults in Kuala Lumpur, Malaysia. BMC Public Health. 2011;11(1):735.

31. Moy FM. Vitamin D status and its associated factors of free living Malay adults in a tropical country, Malaysia. Journal of Photochemistry and Photobiology B: Biology. 2011;104(3):444-8.

32. Quah SW, Majid HA, Al-Sadat N, Yahya A, Su TT, Jalaludin MY. Risk factors of vitamin D deficiency among 15-year-old adolescents participating in the Malaysian Health and Adolescents Longitudinal Research Team Study (MyHeARTs). PLoS One. 2018;13(7):e0200736.

33. Aljefree NM, Lee P, Ahmed F. Knowledge and attitudes about vitamin $\mathrm{D}$, and behaviors related to vitamin $\mathrm{D}$ in adults with and without coronary heart disease in Saudi Arabia. BMC Public Health. 2017;17(1):266.

34. Boland S, Irwin JD, Johnson AM. A Survey of University Students' Vitamin D-Related Knowledge. J Nutr Educ Behav. 2015;47(1):99-103.

35. Salmanpour VA, Ibrahim HS, Salameh AG, Yahya AM, Debal BK. Vitamin D deficiency: knowledge and practices among the adult population in Sharjah, United Arab Emirates. Archives of osteoporosis. 2016;11(1):15.

36. Alshamsan FM, Bin-Abbas BS. Knowledge, awareness, attitudes and sources of vitamin D deficiency and sufficiency in Saudi children. Saudi Med J. 2016;37(5):579.

37. Arora H, Dixit V, Srivastava N. Evaluation of knowledge, practices of vitamin D and attitude toward sunlight among indian students. Asian J Pharm Clin Res. 2016;9(1):308-13.
38. Wang H, Chen W, Li D, Yin X, Zhang X, Olsen $\mathrm{N}$, et al. Vitamin D and chronic diseases. Aging Dis. 2017;8(3):346.

39. Harinarayan CV. Vitamin D and diabetes mellitus. Hormones (Athens). 2014;13(2):163-81.

40. Mulligan ML, Felton SK, Riek AE, BernalMizrachi C. Implications of vitamin D deficiency in pregnancy and lactation. Am J Obstet Gynecol. 2010;202(5):429. e1-. e9.

41. Kim YJ. Comparison of the serum vitamin D level between breastfed and formula-fed infants: several factors which can affect serum vitamin D concentration. Korean J Pediatr. 2013;56(5):202.

42. Wagner CL, Greer FR. Prevention of rickets and vitamin D deficiency in infants, children, and adolescents. Pediatrics. 2008;122(5):1142-52.

43. Al Bathi BA, Al Zayed KE, Al Qenai M, Makboul G, El-Shazly MK. Knowledge, attitude and practice of patients attending primary care centers toward vitamin $\mathrm{D}$ in Kuwait. Alexandria Journal of Medicine. 2012;48(3):277-82.

44. Reichrath J, Nürnberg B. Cutaneous vitamin D synthesis versus skin cancer development: the Janus-faces of solar UV-radiation. Dermatoendocrinol. 2009;1(5):253-61.

45. Becker $\mathrm{MH}$. The health belief model and sick role behavior. Health Educ Monogr. 1974;2(4):409-19.

46. Audrey Sharmaine A/P Rajaretnam MAA, Hasanain Faisal Ghazi. Knowledge Regarding Vitamin D Among Private University Students in Malaysia. Annals of Nutritional Disorders \& Therapy. 2014;1 (2):1008. 